\title{
DRIP IRRIGATION IN PAKISTAN: STATUS, CHALLENGES AND FUTURE PROSPECTS
}

\author{
Khan Muhammad Usman ${ }^{1}$, Tayyab Muhammad ${ }^{2 *}$, Majeed Majid ${ }^{3}$, \\ Shariati Mohammad $\mathrm{Ali}^{4}$, Rashidzadeh Shilan ${ }^{5}$, Mohammadlou Alireza ${ }^{5}$, Plygun Sergey ${ }^{4}$ \\ ${ }^{1}$ Department of Energy Systems Engineering, University of Agriculture, Pakistan \\ ${ }^{2}$ Punjab Bio-Energy Institute (PBI), University of Agriculture, Pakistan \\ ${ }^{3}$ National Institute of Food Science and Technology, University of Agriculture, Pakistan \\ ${ }^{4}$ Orel Sate Agrarian University \& All-Russian Research Institute of Phytopathology, Russia \\ ${ }^{5}$ Saei Nonprofit Institute, Gorgan, Iran \\ *E-mail: engr.tayyab@uaf.edu.pk
}

\begin{abstract}
Efficient use of water for agriculture production is highly emphasized by the Government of Pakistan due to limited available water resources to meet the growing need of ever increasing population. With the passage of time water resources are depleting and becoming limited for food production. The freshwater that can be taped is only $0.007 \%$ of the total available water. About $95 \%$ of the water is used for agriculture in Pakistan and produces more than $90 \%$ food from irrigated agricultural land. Huge water competition problems have to face by farming community in irrigated agricultural areas in the form of low crop yields, water logging and salinity, lack of reservoirs, population pressure, etc. Drip irrigation system can help to use the scarce available water more efficiently. The potential areas for drip irrigation system are; areas of water shortage and valuable crops, fringe areas, sandy areas, etc. There is a need to develop energy and water efficient irrigation systems to reduce the cost of micro-irrigation systems. The training of the farmers regarding installation, operation and maintenance is of vital importance in the success of these systems.
\end{abstract}

\section{KEY WORDS}

Population, food production, freshwater, yields, drip irrigation, energy, micro irrigation system.

Water plays an important part to fulfil the water requirements particularly in photosynthesis. It helps in transportation of nutrients from soil to the plants which are essential for their growth. About $70 \%$ of total earth's area is covered by water. Out of which, fresh water is about $2.5 \%$ only, which is mostly available in the frozen form, soil water or in deep water bearing strata not freely reachable. Indeed economically available water is $<1 \%$ of the world's freshwater which is in the form of water ponds, rivers, storage structures and shallow aquifers (World Meteorological Organization, 2000) which is about $0.007 \%$ of the total earth's water. Water plays an important role for existence of life on earth. Throughout the world, water is used for different purposes and agriculture is one the major sector of water use, which holds about 17 percent of cultivated land (approx. $275 \mathrm{~m} \mathrm{ha}$ ) and become a reason for nearly 40 percent of world food production (IPTRID, 1999).

In order to increase yield of food products to fulfil the huge requirements world population in $21^{\text {st }}$ century will need to bring about a «Blue Revolution» to balance the "Green Revolution» of the $20^{\text {lh }}$ century (Rajaram \& Borlaug, 1997). The low income groups or less developing countries drawing less water per capita annually in relation to high income groups (Fig. 1). The water consumption rate per capita is low (39\%) in agricultural sector by high income groups and high (91\%) by low income groups (World Bank, 2008). Pakistan has very poor water productivity $\left(0.6 \mathrm{~kg} / \mathrm{m}^{3}\right)$ in comparison with India and California $\left(1.5 \mathrm{~kg} / \mathrm{m}^{3}\right)$ (Qureshi, 2011). To overcome the issue of food security water productivity should be improved by adopting different efficient irrigation systems.

Pakistan lies in the region of low rainfall area which is about less than $100 \mathrm{~mm}$ in lower Indus plains to more than $750 \mathrm{~mm}$ in the northern areas, which is less than crop water 
requirements of different regions as $1487 \mathrm{~mm}$ in Jacobabad (Sindh), $900 \mathrm{~mm}$ in Parachinar (Khyber Pakhtunkhwa), $1280 \mathrm{~mm}$ in Faisalabad (Punjab) and $1400 \mathrm{~mm}$ in Turbat (Balochistan) reported by Allah Bakhsh and Awan (2002). However, water saving irrigation method is needed to fulfill the crop water requirements. Modern irrigation systems play a vital role dearth improvement than any other public improvement in arid and semi-arid climate (Caruthers, et al. 1997).

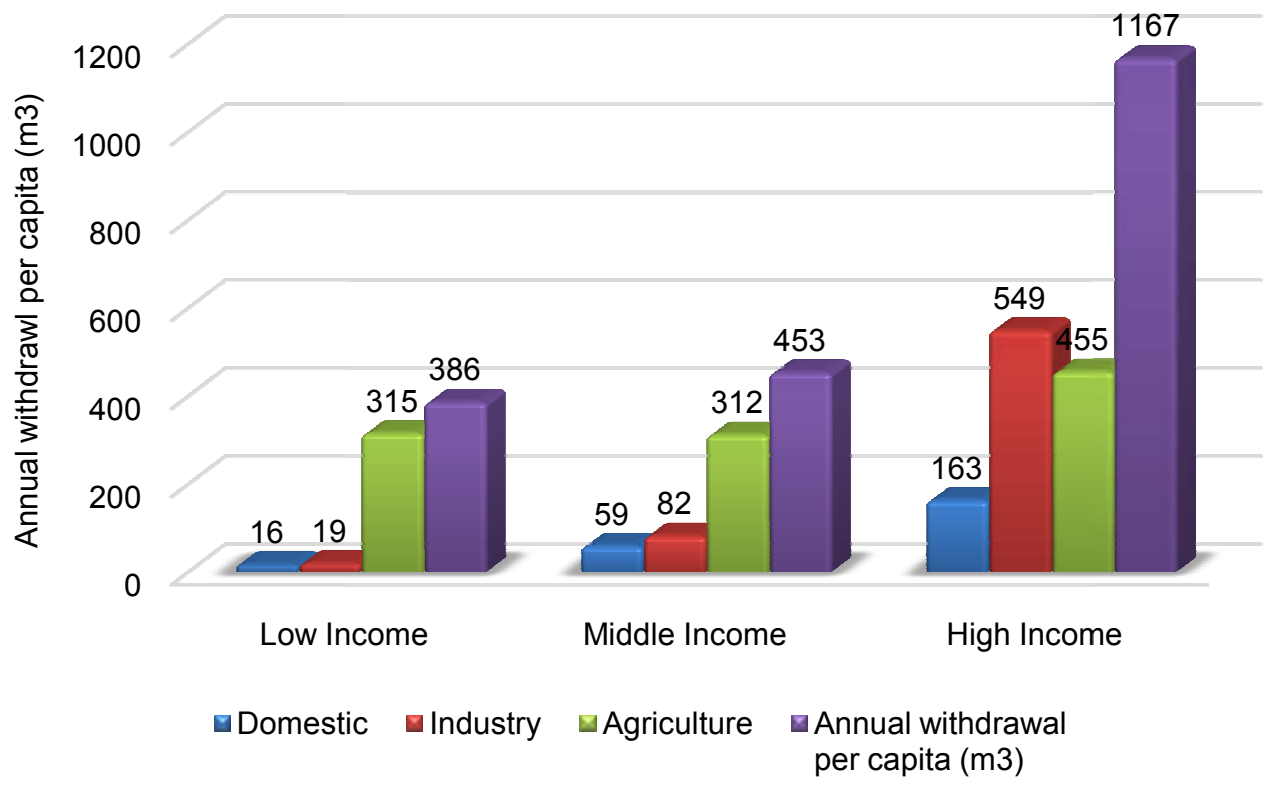

Figure 1 - Water withdrawals by different sectors and income groups (Source: World Bank 1999)

Importance of irrigated area. The total worlds area comes under irrigation systems was about 8 million hectares (mha) in 18the century, 48 mha in $19^{\text {th }}$ century and 272 mha at present. Although irrigated area is $18 \%$ of the cultivable land but it accounts for $40 \%$ of all crop production and almost $60 \%$ of cereal production in many countries.

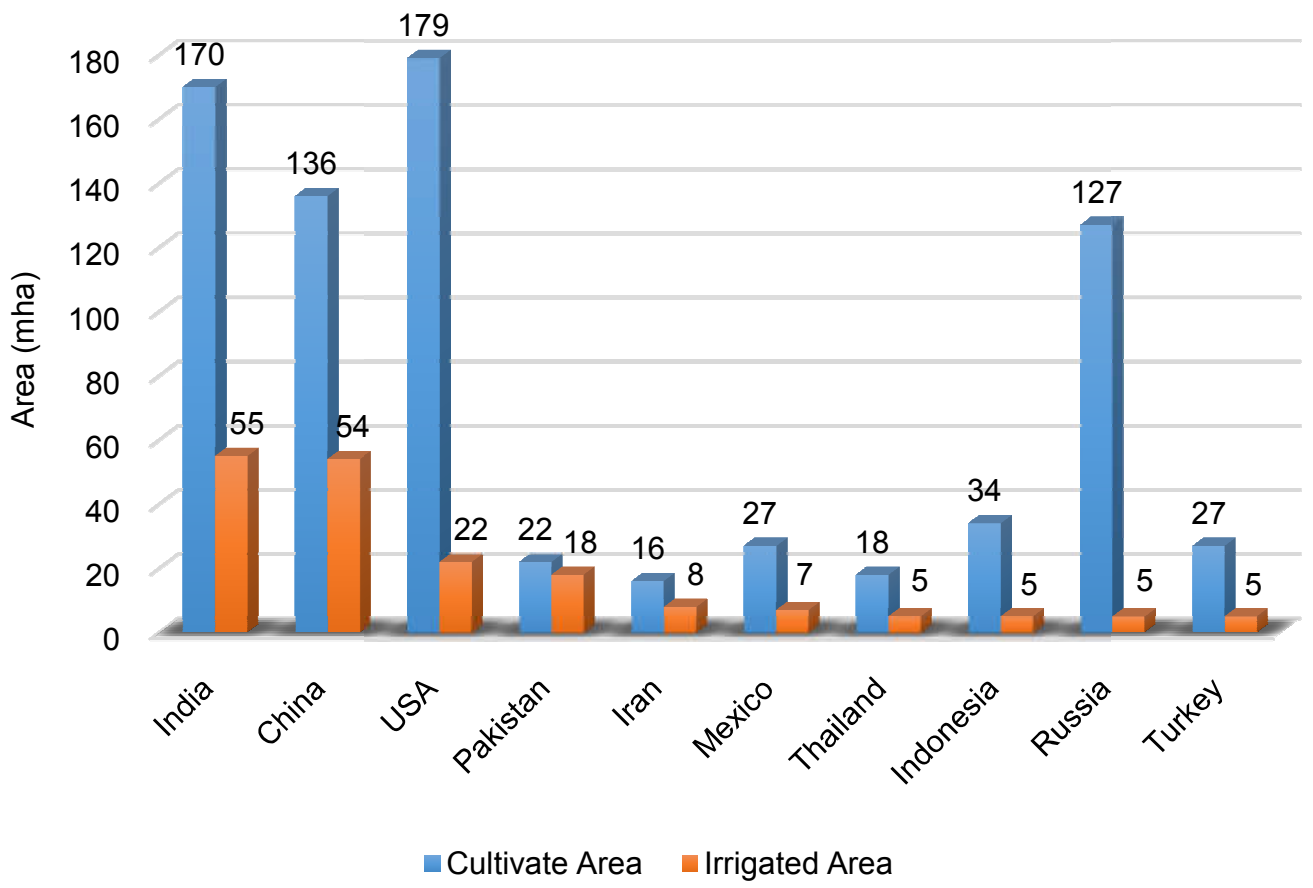

Figure 2 - Cultivated and irrigated areas for the top ten countries with the largest irrigated area (Source: Schultz et al. 2005) 
Most of the crop production comes from the irrigated agricultural lands which is about $90 \%$. World statistics showed that, major (55 mha) irrigated agricultural lands in India then China, USA and Pakistan (Figure 2). It is clear from the graph (Figure 2) Pakistan has the largest connecting canal system for irrigation and lies at $4^{\text {th }}$ position regarding irrigated area. Worldwide withdrawal of water from rivers and underground water sources for irrigating lands is about $70 \%$ whereas $95 \%$ in Pakistan. Therefore, there will be great impact on crop yield by adopting new efficient irrigation systems.

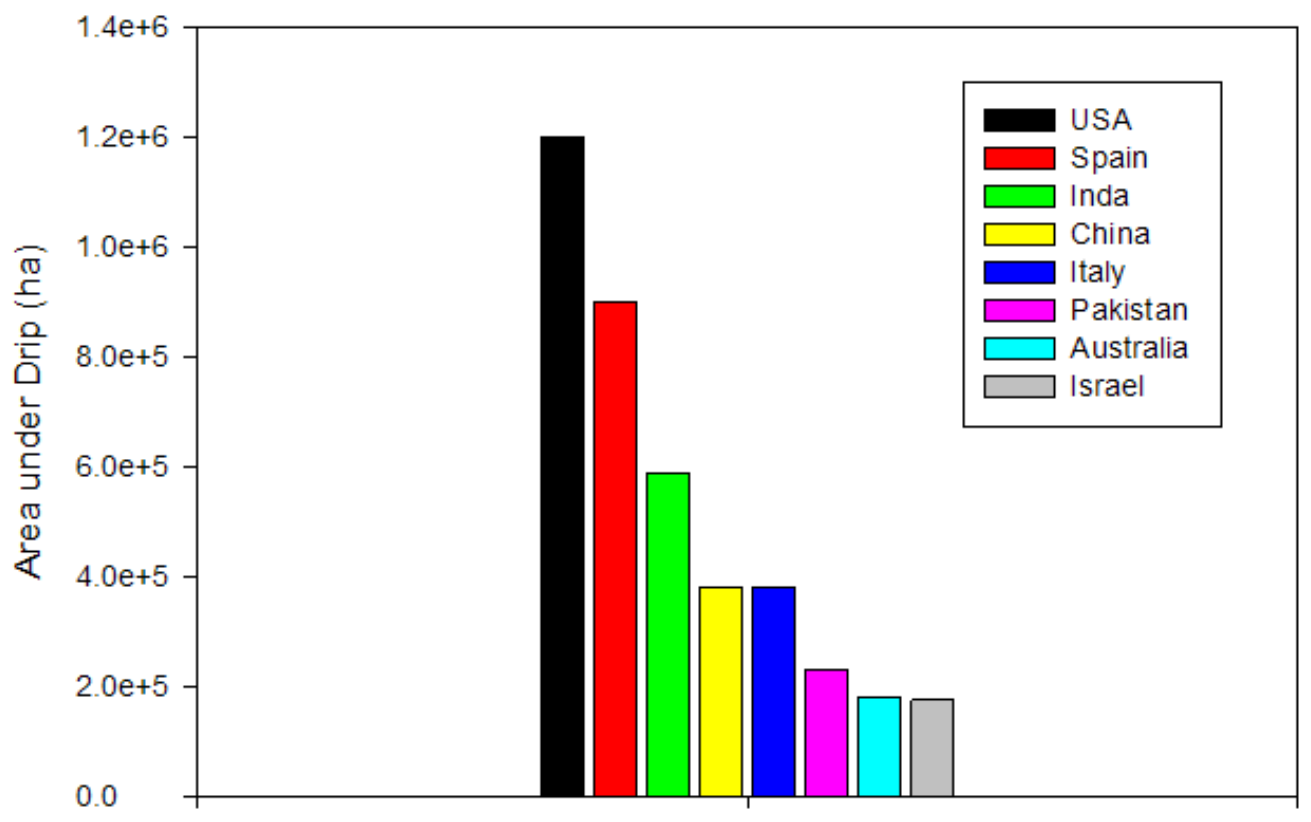

Figure 3 - Hectares under drip irrigation (Source: Kulkami et al. 2006)

The purpose of this study is to show the significance of irrigation system, issues and challenges of the irrigated agriculture, needs, benefits and limitations of drip-irrigation system. Its technology development and indigenization, local manufacturing, availability of materials in the country, adoption of the technology, present state and future needs of the micro irrigation have also been described.

\section{LIMITATIONS OF IRRIGATION SYSTEM}

Foremost Goals of Irrigation in Pakistan. Major improvements in canal systems was initiated in sub-continent regions in the middle of $19^{\text {lh }}$ century based on the objectives as:

- To protect the region from starvation;

- To explode new income generation targets for government;

- To enhance the production rate in limited available water;

- To maximize public profits from uniform supply of available water resources.

Crop yield was maximized by spreading thin layer of available water. The available sources of canal water was appropriate to irrigate only $1 / 3^{\text {rd }}$ of the command area (Bandaragoda and Bedridden, 1992). Production of agricultural commodities is about $90 \%$ by irrigating of about $85 \%$ of cropped area.

Main Concerns and Challenges. There are a number of issues regarding irrigation of agricultural fields throughout the world some of them are as follows:

- Growing population resulting water scarceness per capita;

- Less growth in development of water resources;

- Frequent droughts due to climatic variations;

- Less storage structures and sedimentation issues;

- Low irrigation effectiveness and yield; 
- Groundwater depletion due to over-pumping;

- Water logging and salinity;

- Contamination of surface and ground water resources.

Constraints in Irrigated Agriculture in Pakistan. There are many concerns regarding irrigation systems to fulfil the feed requirements of the growing population and in getting selfreliance in food.

Lack of Reservoirs. Pakistan has few storage structures which is about $15 \%$ capacity of the yearly rivers flows whereas $400 \%$ in Colorado River basin in USA (Frederiksen, 1996). World Bank (2005) reported that, Pakistan has only 30 days water storage capacity, storage for India ranged between 122-220 days, for South Africa 500 days and Colorado River can store up to 900 days of the river flow.

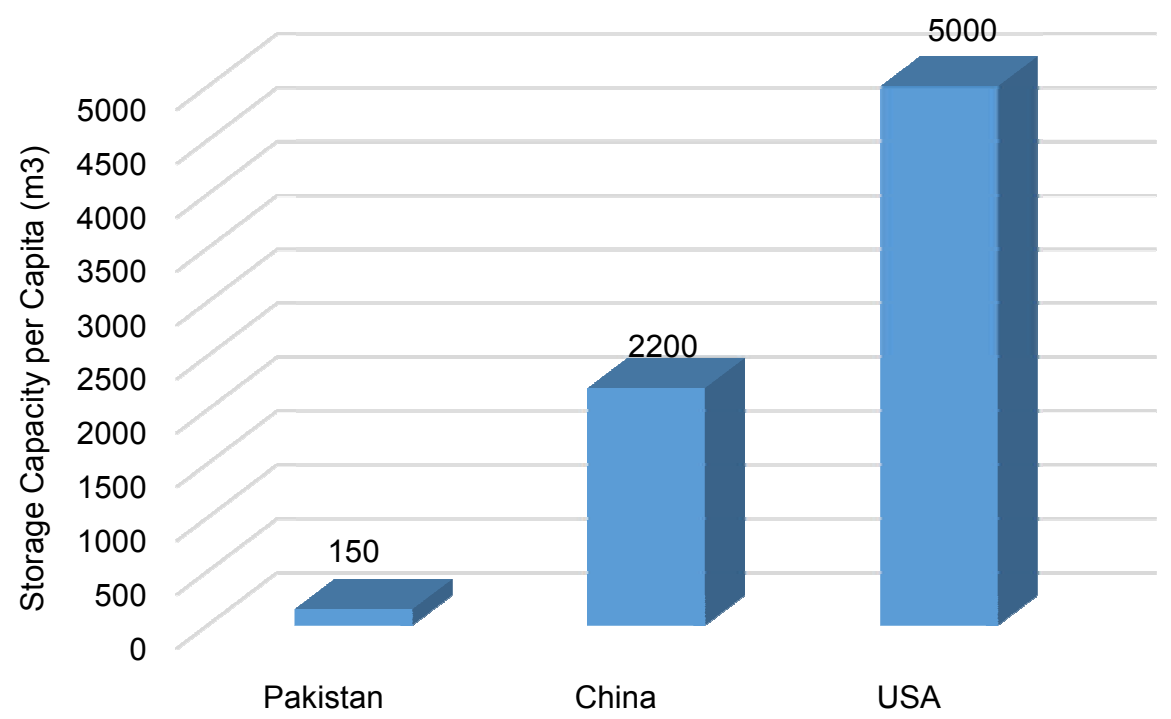

Figure 4 - Country water storage capacity per capita (Source: World Bank 2005)

Population Pressure. It is clear from the graph (Figure 5) the rapid increase in population of Pakistan. The water availability per capita has reduced from $5300 \mathrm{~m}^{3}$ in 1951 to $1200 \mathrm{~m}^{3}$ in 2000 as against the international standard of $1000 \mathrm{~m}^{3}$ (Published in The Express Tribune, March 23 ${ }^{\text {rd }}, 2014$ ).

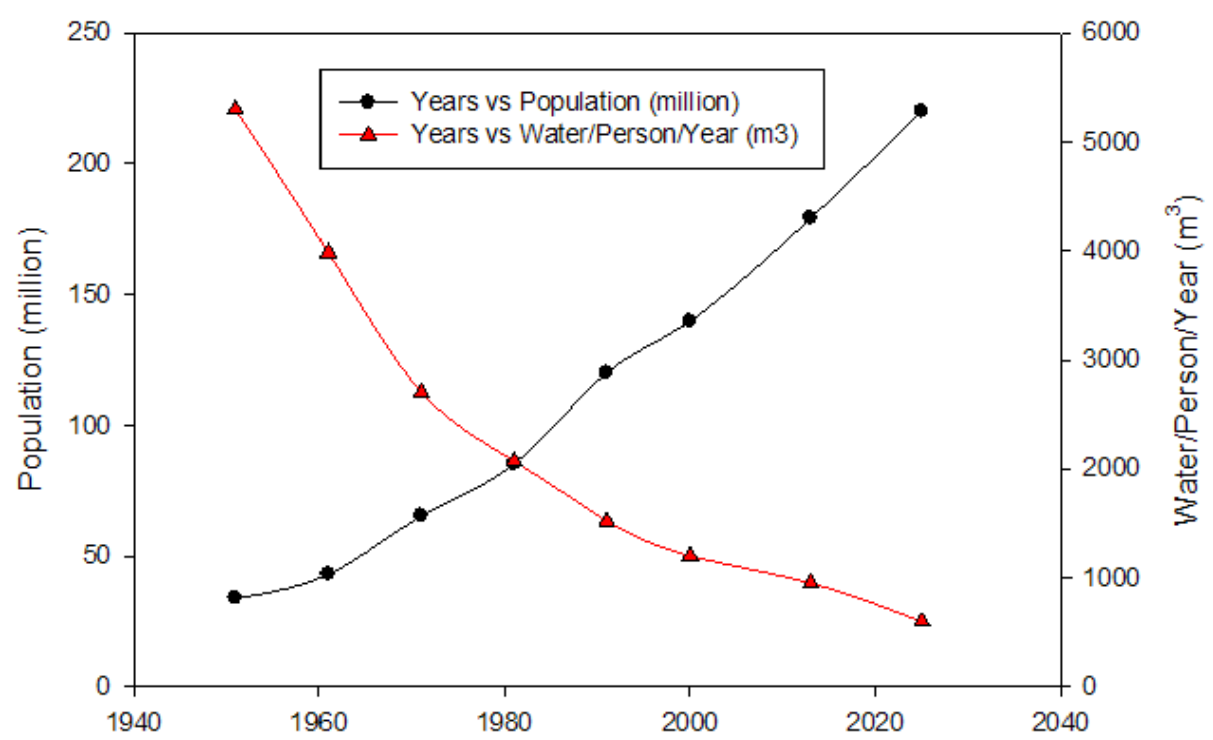

Figure 5 - Declining availability of water in Pakistan (m3/capita/y) 
Water logging and Salinity. Pakistan is facing a severe problem of water logged and saline soil in agriculture sector due to dry climate, uneven landscape, huge leaching, deprived and old fashioned water application approached, poor drainage facilities, unsatisfactory and irregular irrigation and poor quality groundwater. In early 1960's, due to water logging and salinity problems resulted in loss of 40000 ha cultivable land. By June 2001 , problem of salinity and water was tackled by WAPDA by the construction of surface and sub-surface drains on 7.35 mha (WAPDA, 2003). The depth to water table is less than $1.5 \mathrm{~m}$ during the months of April/June on an area of about $2.25 \mathrm{mha}$ since 1985 . The land effected by surface salinity has decreased from $42 \%$ in 1960 's to $25 \%$ in $1977-79$.

Declined Agricultural Productivity. Average yield of agricultural commodities is low even after having favorable environment (weather, land and water resources) as compared to other countries. Pakistan produces only $50 \%$ of wheat production of India and only $30 \%$ of USA. The discussed problem lead the scientists to efficient water application methods by considering crop water requirements to improve productivity of agri-products. It is shown in the graph (Figure 6$)$ cultivable waste $(9.7 \mathrm{mha})$ can be productive with the availability and efficient use of available water resources.

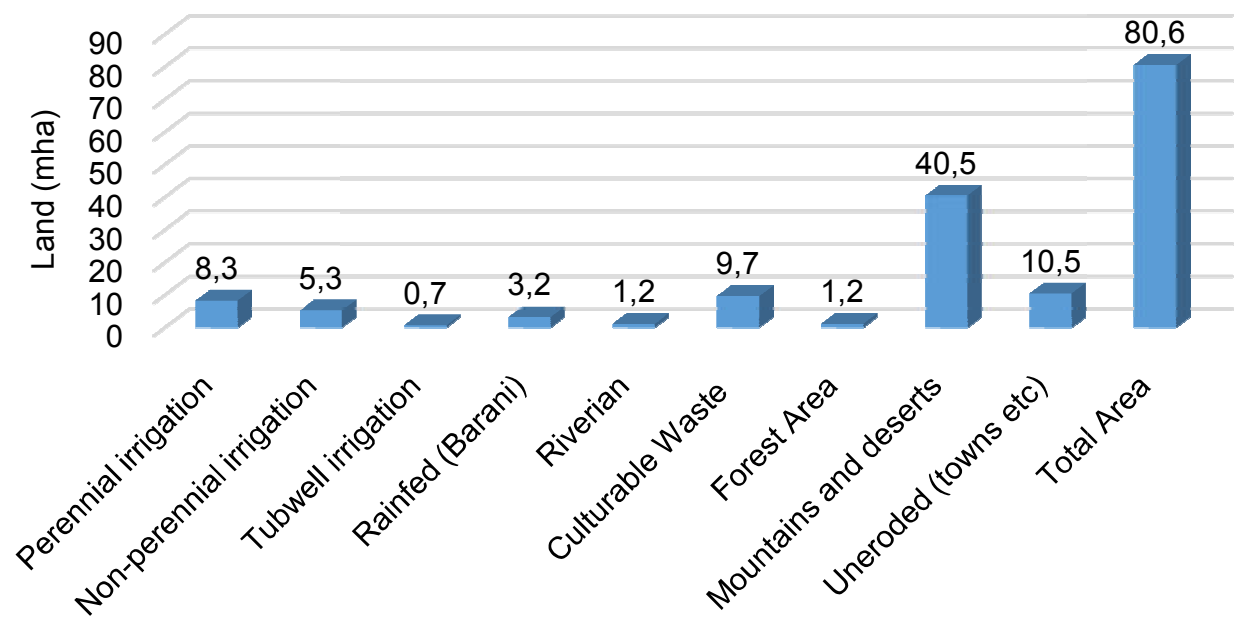

Figure 6 - Area Distribution in Pakistan

Water shortage against Demand. Quantity of water is very limited whereas demand is increasing with growing world population Biswas (1996) reported that water requirements in developing countries as follows: huge quantity of water is required to fulfil the needs of food requirements of growing population; water requirements for drinking purposes, livestock and power generation also increased; from socio-political point of view water becomes very important; new developments in water storage structures will be more costly and needs more time as compared to explore established modern water efficient systems.

Table 1 - Water availability and demand at the farm-gate

\begin{tabular}{|c|c|c|c|}
\hline Item & 2001 & 2004 & 2011 \\
\hline \multicolumn{3}{|c|}{ Water Availability (mha.m) } \\
\hline Surface water & 10.41 & 10.47 & 11.96 \\
Groundwater & 6.17 & 6.17 & 6.17 \\
Total & 16.58 & 16.64 & 18.13 \\
\hline \multicolumn{3}{|c|}{ Water Demand (mha.m) } \\
\hline Irrigation & 16.67 & 17.68 & 20.93 \\
Non-irrigation & 0.73 & 0.80 & 1.09 \\
Total & 17.40 & 18.48 & 22.02 \\
\hline Shortfall & 0.82 & 1.84 & 3.89 \\
\hline
\end{tabular}

Ten Years Perspective Development Plan 2001-2011 (GOP, 2001). 
Similar situation has been depicted for Pakistan in the Ten-Year Perspective Development Plan 2001-2011 (Table 1). There was shortage of available water by $5 \%$ and $11 \%$ during year 2001 and 2004, respectively. The shortfall in the available water will be about $1 \%$ in year 2011. A WAPDA study indicated that the annual shortage of water supplies over crop water requirements is $18 \%$. Crop season wise, this shortage is $35 \%$ during Rabi and $25 \%$ during Kharif (Kahlown \& Majeed, 2004). Thus, there will be insufficient water to satisfy the demands and share of irrigation water will decline. Therefore, irrigation will have to become more efficient.

\section{DRIP IRRIGATION TECHNOLOGY}

Need for Drip-Irrigation. Trickle irrigation and its different types such as drip irrigation, micro-sprinkler, bubbler and sub-surface irrigation are called micro irrigation. In micro irrigation water is conveyed through pipe system almost directly to each plant and the soil immediately surrounding each plant is wetted. Water is applied to the crop on a low tension and high frequency basis and very high water use efficiency is possible. Micro-irrigation systems are most favorable and feasible for those areas where surface irrigation is not suited or land reforming needs huge funds. In irrigated areas, especially at tail-end reaches and for sodic soils, there is a shortage of canal water supplies. The micro-irrigation systems can provide light and frequent irrigations. Shallow and frequent irrigation to sodic soils helps to avoid ponding and thus emergence of crops is much better.

Dry spells and droughts affect the production and quality of high value fruits. The micro-irrigation can help for life saving irrigation with small quantity of water. The application of chemical and organic fertilizers through micro-irrigation is very efficient. To bring more area under irrigation micro-irrigation systems are required to be used in the country. To overcome the problems of inadequate water resources required in case of surface irrigation, the micro-irrigation systems can help to improve field water application efficiency which helps to overcome the problems of low crop yield and low cropping intensity.

Benefits of Drip-Irrigation. Under proper system management, little water is lost to deep percolation, consumption by weeds, or soil surface evaporation. Research results reported in the United States indicate that yield of cotton is increased by more than 8 percent and 24 percent water is saved by drip irrigation. While using 24 percent less applied water as compared to surface irrigation. According to report, drip irrigation was also an effective method of irrigation in controlling return flow volume and it also maintain low salinity levels in soil near by the emitters. In addition to reduced irrigation water requirements and minimization of return flows, drip irrigation has other positive advantages, which are as follows:

- Effective water control is possible with drip-irrigation system, water can be applied very efficiently. The portion of the soil with active roots needs to be irrigated, and soil evaporation losses can be reduced to a minimum. The low rate of water application reduces deep percolation losses;

- High temporal soil water level can be maintained with drip-irrigation system. This results in a favorable response by most crops in increasing yield and quality;

- Drip-irrigation system is generally permanent and have low labor requirements;

- Fertilizer can be applied through drip-irrigation system using fertilizer injectors. Effective control of water results in control over fertilizer application. However, the small amount of water lost through deep percolation results in minimum loss of fertilizer through leaching;

- Wetted surface is only a fraction of the total soil surface. Consequently, there is a reduced potential for weed growth;

- Plant canopy is completely dry under drip-irrigation system. It reduces fungus incidence and other pests, which depend upon a moist environment;

- Matric and osmotic potential are additive. The maintenance of a low matric potential is possible with drip-irrigation system. This results in a lower overall potential, and 
hence a reduced stress under saline conditions. Therefore, some of the crops can be grown in areas, which would otherwise be unsuitable with conventional systems. The upper limit of suitable water for furrow irrigation is about $0.75 \mathrm{dS} / \mathrm{m}$, while for trickle irrigation, water as salty as $4 \mathrm{dS} / \mathrm{m}$ has been used. Water with as little as 3 milliequivalents/litre of sodium can be detrimental in sprinkler systems due to leaf burn;

- Experiments on crops like tomatoes, grapes and sugar beets have resulted in significantly earlier maturation attained than with other irrigation systems;

- Soil surface crusting is a significant problem in some soils. This can reduces emergence of plants, even if these have germinated properly. By maintaining constant high moisture contents, soil surface crusting can be eliminated;

- There is no loss at the edge of fields as can occur through wind drift of sprinkler systems or runoff from the surface systems;

- Root penetration in some soils is minimal at low water contents; the high average water contents maintained with drip-irrigation system reduces this problem;

- Theoretically, water can be applied with drip-irrigation system at rates equal to the plant water use rate.

A wetted profile develops in the root zone beneath each emitter. The shape of the profile is dependent on soil characteristics and is limited by horizontal flow constraints of the soil. The surface area between plant rows is dry, receiving moisture only from rainfall. Dripirrigation system provides controlled irrigation for optimum yield for variety of crops.

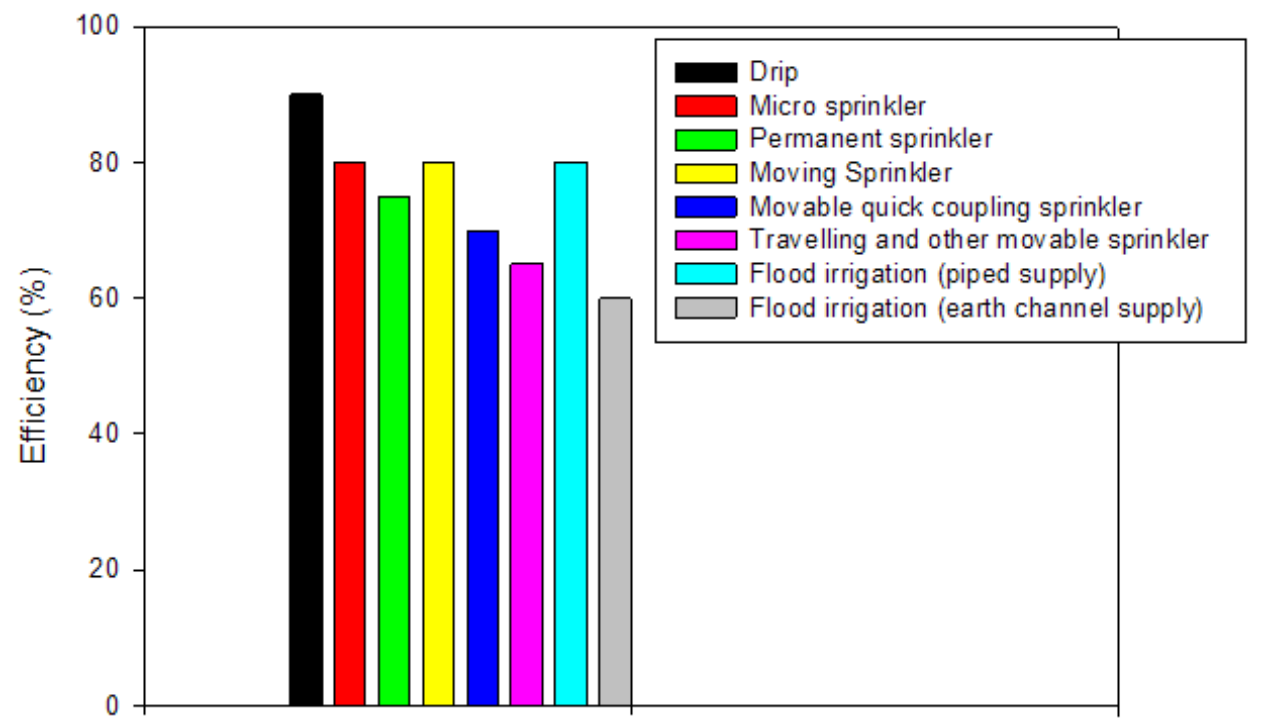

Figure 7 - Efficiencies of irrigation application systems.

Source: South African Irrigation Institute, 2005.

Potential Areas for Drip-Irrigation. Initial capital cost of drip irrigation is considered to be a hindrance for its adoption on large-scale. Therefore, the high installation and operational cost restricted its application to the vegetables and fruits in specific areas. These areas include the following (Bhutta \& Azhar, 2005):

- The areas where high value crops are grown and value of water is high e.g. Balochistan Province;

- The areas where fruits, high value vegetables and fodder are grown like green belts in the urban areas;

- The areas having groundwater is of low quality like Thar and Cholistan;

- The area which require massive investments for the surface irrigation like uncommanded sandy areas within Indus basin;

- Areas where high value crops are grown on the terraces like Pothwar plateau and Northern areas; 
- Command areas of small dams like Khanpur dam, where citrus and leachi orchards are grown and the value of fruit is exceptionally high.

Drip-irrigation system utilize pipes to convey water to the crop fields or directly to plants which develops most of the sandy lands and the soils with irregular geography and salinity problems. Thus, the resources of water can be extended greatly and in-cultivable land can also brought under cultivation by using of drip irrigation. There is little problem regarding the initial cost highly skilled manpower for drip irrigation systems, which have already been minimized due to large scale adoption of this system in the world.

The cost of drip irrigation mainly depends on the spacing of laterals. For fruit trees, the micro-irrigation system is even more economical. The main component of drip system which effects the cost is the lateral lines; however, the wider the row spacing the lesser the initial cost. Crops like grapes, almond, apples, papayas, guava, citrus, coconut and other fruit trees can be grown well with drip-irrigation system.

\section{TECHNOLGY DEVELOPMENT AND INDIGINIZATION}

Factors in selection of Drip Irrigation. A number of factors should be considered during the selection of irrigation system, these factors may vary with respect to location, topography, cropping pattern, cost of system, and cost of operation, availability of relevant labor, soil conditions, agricultural influences and availability of water. Selected systems should be friendly to other agricultural practices viz. inter-culturing, land development, sowing and cutting operations.

Economic Consideration. The selection of drip-irrigation system is a cost beneficial step. Some of them have high cost per hectare and their use is only for costly crops. The systems other than drip-irrigation are more laborious, and some of these are equally high cost of operating. Drip-irrigation systems are cost-effective for fruit plants and creeper-type vegetables and very costly for field crops. Moreover, some of the systems have restrictions in relation with soil type or the topography on which these systems can be utilized. The selection of an irrigation system should be based on expected life circle of the system, fixed charges, and annual operational charges which are considered in the analysis.

Topographic Limitations. Limitations while selecting an irrigation system due to topographical characteristics are as: level of ground-water, the low height of the water source, field borders, field area, the citation of roads, lines of electricity water, form of the field, and field gradient. The slope of the field plays a vital role as some of the micro irrigation systems can work on gradients up to $20 \%$ or more. Type of the system is also determined by the shape of the field. Micro-irrigation technology can be adapted to almost any shape of the field/farm.

Soil Characteristics. Type of soil, water holding capability of soil, the effective depth of soil and intake are the most significant causes for the system selection. For example, sandy soils needs more water and receive high amount of trickle and sprinkler irrigation systems, while the clay soil have not these potentials. The size of the irrigation system and irrigation application as showed by a sandy soil which have low water holding capability will effect by water holding capability, which needs regular and light uses of water. The contact of water with soils due to some biological, chemical, and physical procedures has a little impact on the hydraulic properties and tilt. Crusting and erosion should be under consideration in the designing of irrigation system, and the spatial division of soil characteristics may be a significant constraint on some techniques of applying irrigation.

Water Supply. Factors like quality, quantity, and time-based division of irrigation water have considerable effect on irrigation methods. Crop water needs are essentially constant during the growing period although different in size. A small, readily existing water source is best consumed in a small size irrigation system with many applications. The depths used per irrigation are small in comparison to a system having a huge discharge available often. Quality of water in combination with the application rate of irrigation must be weighed. The most significant problem which is observed is salinity. Water with high contents of salts should be used more frequently and in huge quantity than pure water. 
Crop Factors. There are following factors related with crops to be sown effect the selection of irrigation system as:

- Bearing of the plant during both growth and ripening to aeration of soil and salinity;

- For maximum production temporal sharing of water is necessary;

- Economical cost of the crop.

Selection of Drip Irrigation System. The factors discussed above, a selection of best irrigation system is necessary. For planting of fields with trees and perennial plants of same characteristics, the systems which are permanently placed are best for working. A system is used for irrigating vegetables whose parts can be fragmented to facilitate the essential traditional processes. It should be noted, however, that trickle irrigation systems are widely used in row crops. Drip-irrigation system is energy demanding and high initial investment. But, at the same time, it is labor, water and fertilizer efficient. There is no need of investment in leveling of land, but usually this system requires scheduled maintenance operations. From economy point of view the main advantage of drip-irrigation system in providing an economical or low cost means of water, fertilizer and pesticide applications.

Local Manufacturing. The cost of laterals which are used deliver water from pumping unit to the specific plant is high in case of drip irrigation. Therefore, efforts should be made to produce pipes for laterals in the country. The black colored poly-ethylene pipes which have minimum density, ultraviolet stabilizers and carbon substances have been locally produced using locally available materials and technology. The Plastic Technology Centre, Karachi provids technical support in analyzing the material, finding constituents of the pipes and testing the material.

The next important component of the drip-irrigation system is the emitters. The pressure compensating turbo emitters, variable flow spiral emitters and LDPE micro-tubing emitters have been locally produced. The fittings and accessories like push-fit connections and push-fit reducer adapter for $13 \mathrm{~mm}$ diameter lateral, quick coupler for 25 and $50 \mathrm{~mm}$ diameter pipes, filter, etc have also been developed locally. The other fittings like gate valves, elbows, tees, etc can easily be obtained from the local market.

Availability of Systems' Components. All the components of the drip-irrigation system have been locally manufactured using locally available materials and technology in collaboration with local industry. The technical support was provided by WRRI-NARC, Islamabad. The driop-irrigation system components are now available from Griffon Industrial Corporation, Lahore and New Tech (Pvt) Ltd., Islamabad. In fact many other industries are now producing LDPE pipes which can be used for drip-irrigation system.

\section{ADAPTATION OF DRIP RRIGATION IN PAKISTAN}

Drip irrigation systems are basically used for irrigating high value fruit trees and orchards. Efforts have been initiated to introduce micro sprinklers to fulfill the needs of the farmers interested in inter-cropping within early 4 to 5 year's when the crop is at growing stage. Some of the farmers have approached WRRI for designing of trickle irrigation system for vegetables, especially potato. The micro-irrigation systems have been fitted in the water precious zones, like, Baluchistan, Northern areas, D.G. Khan, Kohat, Bahawal pur, Nowshera, Hari pur and Attock. These systems have been installed for fruit trees of guava, loquat, lemon, citrus, leachi and apple. During the drought periods, a group of farmers from Sargodha district approached WRRI-NARC and demanded micro-irrigation system for their farms. A three acre demonstration plot has been establish for orchard at Bhalwal, Sargodha.

The conventional trickle irrigation system provides optimum soil water conditions when properly designed, installed and managed, and requires a minimum of labor. However, at the beginning, the emitters would have to be imported. But, sooner, these would be manufactured in Pakistan. In essence, this form of irrigation involves the use of portable hoses to supply water directly to small basins around each tree or near to each plant. The water will only make exit from the system at and into the basins provided at each tree and there will be no chance for losses except through poor distribution or over-irrigation of the basins. 
The modified hose-fed system is adaptable in Pakistan as it makes a reasonable compromise between labor and resource inputs. These systems should provide optimum water management on all types of soils for a variety of vegetables and fruit orchards. Furthermore, most of the components of these systems can be manufactured from locally available resources by existing industries. The systems need to be designed in a simplified way so that it can be understood and operated by the farming community. These adaptations are also suitable for matured orchards, which were initially developed on flood irrigation and farmers want to change due to shortage of water. Drip-irrigation design for matured orchards, which were raised on flood irrigation, is not only complex due to extended root system but also costly. Therefore, such adaptations are essential for matured orchards to develop feasible and cost-effective systems. LDPE pipes developed for micro-irrigation systems are not sufficiently flexible to use as a hose, which can be moved by labor to reduce the capital cost. Therefore, PVC flexible hose can be used as laterals, which can be moved manually. Modified hose-fed irrigation systems are costly compared to flood irrigation in terms of capital cost, but they are economical in terms of operational cost due to increase in electricity tariff and diesel prices. Furthermore, large discharges are required for flood irrigation. For pipeflow irrigation systems, water is applied directly to plants, which requires much less amount of water. There is a substantial saving in terms of electricity or diesel. Furthermore, the size of the prime mover can be reduced tremendously. The residential electricity connections can be used for small to medium size farms, if sufficient power supply is available.

\section{LIMITATIONS OF DRIP-IRRIGATION}

There are a number of problems and disadvantages with drip-irrigation system. The most important one is that the small flows through emitters require small openings that have historically been plagued by clogging. With the smaller emitter-orifices, more filtering and biological controls are needed. Great advances have been made to rectify this problem, but it will always require the attention of the designer.

Point or strip-wetting is not always an advantage, even though water-savings and weed-control are significant benefits. Salinity tends to accumulate a short distance from emitters and can be transported in the root-zone in case of heavy rainfall. In addition, rootzone tends to be smaller and more densely distributed. This can result in anchorage and aeration problems for some crops. Interestingly, some of the predatory insects' breed in the weeds around a field and some evidence have been reported that drip-irrigation may cause somewhat higher pesticides demand. In windy areas, dry regions between emitters, can pose dust problem. Solid-set structure of drip-irrigation system, along with filtration requirements, makes it a high-cost technology, applicable primarily to valuable row-crops, orchards, and vineyards.

\section{RECOMMENDATIONS AND FUTURE REQUIREMENTS}

Energy and Water Efficient System. At present, many developmental programs are running to control losses of water from the system of water-delivery in the Indus basin. Furthermore, a little effort is made to develop irrigation methods which are efficient. So, a lot of work is necessary to develop already placed surface irrigation and introducing a dripirrigation system of easy to work, flexible to agricultural society, crops and to local environment of the country. If consider the funds required for the improvement of land and drainage within the Indus Basin, funds mandatory for the fabrication of micro-irrigation systems look reasonable.

The main purpose of the study is to maximize net benefits and minimize cost. This is because of the low investment capacity of the small farmers. The cost of energy (diesel and electricity) is increasing day by day. This has made tube well irrigation and micro-irrigation very expensive. This situation demands energy and water efficient irrigation systems. The WRRI-NARC is working on energy efficient and water efficient pumping systems to be developed locally. The initial results of ceramic balls indicated a decrease of about $30 \%$ in 
fuel consumption of diesel engines. A magnetic modifier indicated a decrease of $20 \%$ in fuel consumption of diesel engines. Dhani Buksh et al (2000) indicated that EMz Ceramics for 3 and $8 \mathrm{hp}$ engine pumps provided decrease in fuel consumption of around $25-34 \%$. The testing of this technique has been initiated in irrigated areas of Punjab and Balochistan in collaboration with On-Farm Water Management Directorates.

Design Support. Designing of an irrigation system is basically an art in which efforts are made to increase efficiency and minimize requirement of labor and capital necessities. The WRRI-NARC has developed handbooks in which procedures for designing drip irrigation system have been described in detail. But each farm will have its own design due to difference in soil type, water source, quality of water, capability and capacity of individual farmer, choice of farmer, labor availability, automation required, etc.

There is a need to train engineers in the design of drip-irrigation system so that they can provide service to the interested farmers according to their needs and requirements. In the design process, different alternate options are considered to select the best satisfying design. Sometimes trade-off has to be made from the standard design procedures. Some of the examples of trade-off are as under:

Uniformity of irrigation application influences the system design. For achieving high uniformity in drip-irrigation, each emitter discharge must have minimum variation from the average. This implies that pressure throughout the system must be uniform. Since friction losses in pipe network are unavoidable, the desire to ensure nearly uniform pressure distribution requires that pipe diameters be relatively large and individual pipe lengths be shortened. Thus higher uniformity requires higher costs, which normally will be more than the benefits because of increased yields. In practice, the uniformity in drip-irrigation system design is maintained arbitrarily limiting pressure variation to within $10 \%$ of the average design value, thereby eliminating the uniformity-yield considerations.

There is also a competition between the costs of pumping and the cost of pipe. If the pipe diameters are reduced the head loss in subunits will increase and must be compensated with higher energy. Similarly increasing pipe diameters can reduce the pumping energy. The optimum level will be achieved by minimizing the sum of both pipe and energy costs. The other tradeoffs include labor versus automation which is again related with the system cost and the farmers' preferences. The systematic procedure for optimization requires a mathematical expression of relationship between the optimizing criterion (minimum costs) and the decision variables (pipe lengths and energy costs). Considering socio-economic situation of the farming community in Pakistan, both the decision variables are important. However, in practice, there is flat electricity rates based on, horsepower of the electric motor. Therefore, minimizing energy cost will be an important objective function because electricity is not easily available and farmers now prefer diesel-operated pumping systems.

Further rise in diesel prices and extremely low-efficiency of the prime movers have forced farmers to reconsider electric motors instead of diesel engines with a condition that the size of the prime movers has to be reduced. This reduction is aimed to minimize the energy cost. Some of the farmers have forced the design engineers to even design lowpressure energy efficient systems using single phase electric motors, because they are facing difficulties to obtain and maintain three-phase connection of electricity. Furthermore, optimization of design must be done by considering the operating cost of the system in terms of unit irrigation cost. This will also require clear understanding of the design objectives by the engineers involved in this process.

Services to Farmers. The drip-irrigation system require higher management skills as compared to surface irrigation systems. There is a need to involve farmers in all the processes starting from survey, design, materials selection, installation, operation and maintenance of the system. The active involvement of the farmer is must for the success of the system. The involvement of the farmers' labor who ultimately will be operating the system is an important element in the successful operation of the system.

Farmer's trainings courses should be organized at institutional level or at field level to aware the farmers about the installation, operation and maintenance of drip irrigation system to 
overcome the problems faced by farming community regarding drip irrigation system. A schematic view to spread drip laterals, main and sub-main to facilitate the farmers as follows:

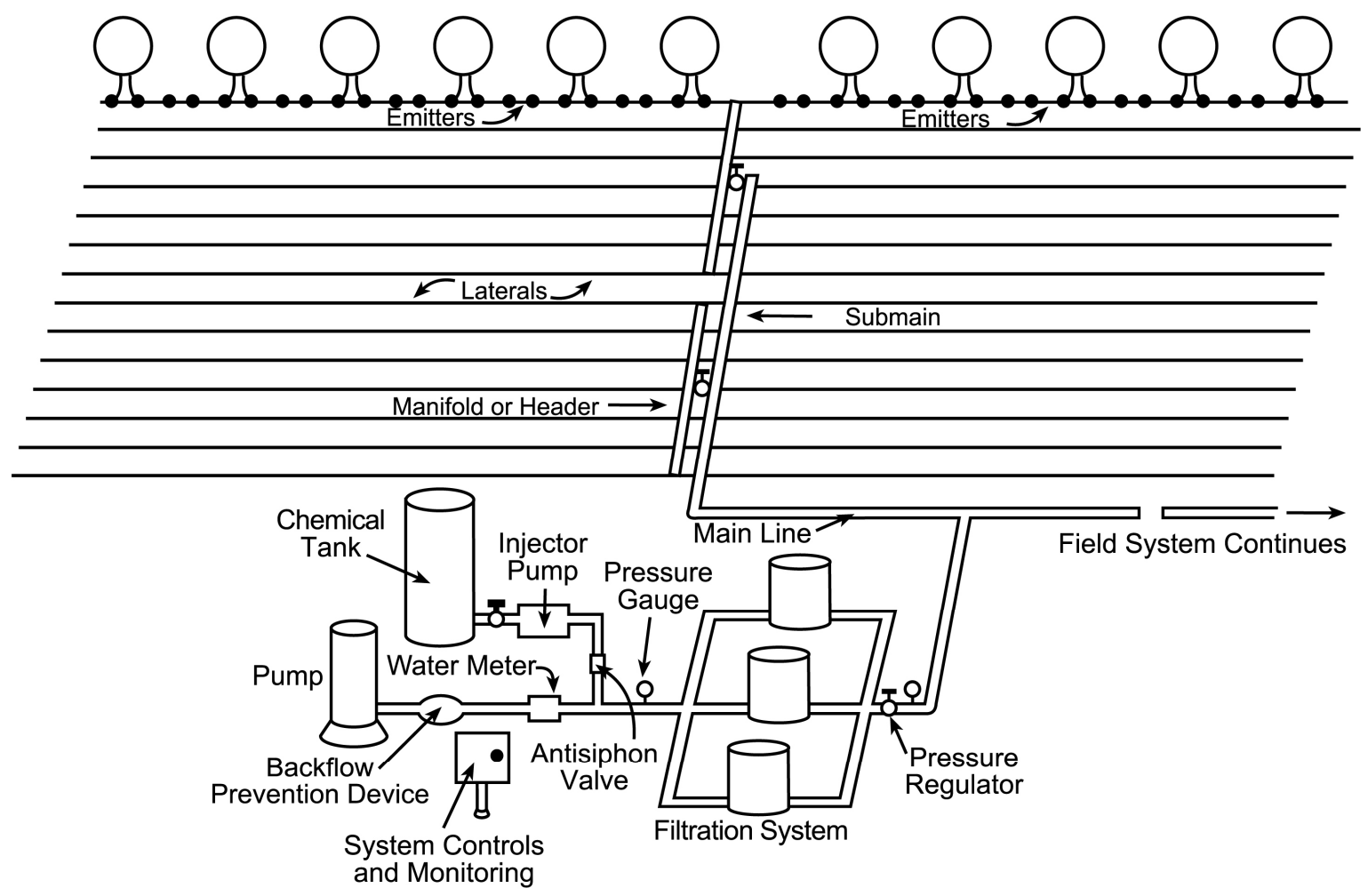

Figure 8 - Schematic View of Drip Irrigation System

There is an urgent need to establish private irrigation companies involving jobless engineers and giving on-job training in the design of irrigation systems. The irrigation companies should not only help in designing and installation of the system but also provide practical training in operation and maintenance of the system and application of irrigation water for different crops and at different crop growth stages.

Initially some financial support in the shape of interest free loans is required for the irrigation companies and government agencies. The WRRI-NARC has started providing onjob training to the jobless Agricultural Engineers in the surveying, designing, installation, operation and maintenance of micro-irrigation systems. The Government of Pakistan is working for providing financial support to the irrigation companies. The experience of establishing private irrigation companies is running successfully in many other countries.

Manufacturing Requirement. The WRRI-NARC has developed handbooks of dripirrigation system in which specifications for manufacturers have also been described for sprinkler and trickle irrigation systems. The important item to be manufactured in the country is the high pressure pumps especially for deep well pumping. The groundwater level in the areas outside Indus basin is deep and centrifugal pumps do not operate satisfactorily in these areas. Some of the imported pumps are available in the country for deep-well pumping but they are quite expensive and out of reach of common farmer.

The joints and fittings for drip-irrigation system have to be developed in the country. Presently the G.I fittings are being used as the polyethylene pipe fittings are not available. The joints and fittings would be cheap if developed locally using polyethylene pipe. The manufacturing of pressure compensating turbo emitters is also required; the financial support is required for manufacturing of quality turbo emitters. Presently, micro-tubing used as emitters in the micro-irrigation systems. 


\section{CONCLUSION}

The cost effective and efficient use of drip irrigation system has a great potential in Pakistan especially when the country is facing severe water shortage problem. There exists a lot of opportunities in Pakistan to get benefits from this sector but this can only be realized by introducing effective policies and strategies at the government level. Moreover, process of exploring these modern technologies can be boosted by developing a sense of responsibility, awareness and necessary training regarding such modern water saving technologies to solve water scarcity issues. The strengthening and effectiveness of research institutes of the country are also necessary which will ultimately lead to a better utilization of water resources.

\section{REFERENCES}

1. Baksh, A. and Q.A. Awan. 2002. Water issues and remedies in Pakistan. Proceedings of the National Symposium on drought and water resources in Pakistan on March 1, 2002 at Centre of Excellence in Water Resources Engineering, University of Engineering and Technology, Lahore, P. 145-150.

2. Bandaragoda, D. J. and M. Badruddin. 1992. Moving towards demand based operations in modernized irrigation systems in Pakistan. International Irrigation Management Institute, IIMI Country Paper, Pakistan - No.5.

3. Bhatti, M.A. 1999.. Water Resources Systems of Pakistan: Status and Issues. A Pakistan Science foundation Publication, Islamabad.

4. Biswa, A.K. 1996. Water for the developing world in the $21^{\text {st }}$ Century. Journal of Irrigation and Drainage, ICID, Vol.45, No. 2, Page 1-12.

5. Buksh, D., Hamid ljaz, S. Ahmad and M. Yasin. 2000. EMz Ceramics for Improving Fuel Efficiency of Diesel Pumpsets in Pakistan. Nature Farming \& Environment - An International Journal. Nature Farming Research \& Development Foundation, Faisalabad, Pakistan.

6. Caruthers, lan; Rosegrant, Mark. W. and Seckler David. 1997. Irrigation and Drainage Systems. 11:83-101.

7. Frederiksen, M.D. 1996. Water Crises in Developing World. Misconceptions about Solutions. Journal of Water Resources Planning and Management, March/April. 1996, P. $79 *-87$.

8. IPTRID. 1999. Poverty reduction and irrigated agriculture. Issues paper No. 1; FAO, Rome, Italy.

9. Kahlown, M.A. and A. Majeed. 2004. Pakistan Water Resources: Development and Management, PCRWR, Islamabad.

10. Rajaram, S. and N:E. Borlaug. 1997. Approaches to breeding for wide adaptation, yield potential, rust resistance and drought tolerance. Paper presented at primer symposia international de trigo, Cd Obregon, Mexico, ' April 7-9, 1997.

11. Shultz, B., CD. Thatta and V.K. Labhsetwar. 2005. Irrigation and Drainage. Main contributors to global food production. Journal of Irrigation and Drainage, ICID, Vol. 54, No. 3, P. 263-278.

12. Bhutta M.N., and Azhar A.H. (2005). A Proposal for Sprinkler Irrigation Model Farm at Mirani Dam Project (MDP), Turbat. IWASRI Internal Report No. 2005/01.

13. Ten Year Perspective Development Plan 2001-11 (GOP, 2001).

14. WAPDA. Annual Report. 2003.

15. World Bank. 1999. A World Bank Policy Paper. The World Bank, Washington D.C.

16. World Bank. 2005. Pakistan Country Water Resources Assistance strategy. Water Economy: Running Dry. Agriculture and Rural Development Unit South Asia Region.

17. World Meteorological Organization. 2000. Comprehensive assessment of the freshwater resources of the world. 